\title{
Genetic variation of Mycobacterium tuberculosis circulating in Kharkiv Oblast, Ukraine
}

\author{
Maya A Dymova ${ }^{1 *}$, Oleksander O Liashenko ${ }^{2}$, Petro I Poteiko², Valeriy S Krutko ${ }^{2}$, Eugeny A Khrapov ${ }^{1}$ and \\ Maxim L Filipenko'
}

\begin{abstract}
Background: A persistent increase of tuberculosis cases has recently been noted in the Ukraine. The reported incidence of drug-resistant isolates of $M$. tuberculosis is growing steadily; however, data on the genetic variation of isolates of M. tuberculosis circulating in northern Ukraine and on the spectrum and frequency of occurrence of mutations determining resistance to the principal anti-tuberculosis drugs isoniazid and rifampicin have not yet been reported.
\end{abstract}

Methods: Isolates of M. tuberculosis from 98 tuberculosis patients living in Kharkiv Oblast (Ukraine) were analyzed using VNTR- and RFLP-IS6110-typing methods. Mutations associated with resistance to rifampicin and isoniazid were detected by RFLP-PCR methods, and also confirmed by sequencing.

Results: We identified 75 different genetic profiles. Thirty four (34\%) isolates belonged to the Beijing genotype and $23(23 \%)$ isolates belonged to the LAM family. A cluster of isolates belonging to the LAM family had significant genetic heterogeneity, indicating that this family had an ancient distribution and circulation in this geographical region. Moreover, we found a significant percentage of the isolates (36\%) belonged to as yet unidentified families of M. tuberculosis or had individual non-clustering genotypes. Mutations conferring rifampicin and isoniazid resistance were detected in $49 \%$ and $54 \%$ isolates, respectively. Mutations in codon 531 of the rpoB gene and codon 315 of the kat $G$ gene were predominant among drug-resistant isolates. An association was found for belonging to the LAM strain family and having multiple drug resistance $(R=0.27, p=0.0059)$ and also for the presence of a mutation in codon 531 of the $r p o B$ gene and belonging to the Beijing strain family $(R=0.2, p=$ 0.04).

Conclusions: Transmission of drug-resistant isolates seems to contribute to the spread of resistant TB in this oblast. The Beijing genotype and LAM genotype should be seen as a major cause of drug resistant TB in this region.

\section{Background}

Tuberculosis remains to this day the most widespread infectious disease in many parts of the world and has high mortality rate. Among the estimated 9 million new cases that are annually recorded, antibiotic drug resistance of Mycobacterium tuberculosis has become an increasing problem. The appearance of multidrug-resistant (MDR)-TB and, more recently, of extensively drugresistant (XDR)-TB is an actual threat to achieve TB control and elimination. Each year over 400,000 new cases of MDR-TB occur and, in every setting XDR cases

\footnotetext{
* Correspondence: maya.a.rot@gmail.com

${ }^{1}$ Institute of Chemical Biology and Basic Medicine, Siberian Branch, Russian

Academy of Sciences, Novosibirsk, Russian Federation, Russia

Full list of author information is available at the end of the article
}

are recognized (although their number is currently unknown) [1]. The use of molecular genetic methods to analyze the population structure of Mycobacterium tuberculosis has enabled data to be collected on the relationship between a specific genotype and its influence on the course of disease [2,3] with the outcome of disease being determined to a large extent by the individual characteristics of the patient and the genetic type of the mycobacterium [4]. Different genotypic families of $M$. tuberculosis have varying degrees of virulence eliciting different immune responses [5], which can be manifested as increased abilities of individual genetic types to acquire drug resistance. This can also affect the results of diagnostic tests, e.g., the interferon-gamma T-cell test $[2,3]$. 
Several researchers have shown a relationship between the genotype of isolate, drug resistance, and the type of genetic mutations responsible for the drug resistance. Isolates of $M$. tuberculosis belonging to the Beijing strain family are associated with drug resistance in Iran, Afghanistan, and Russia [6-8]. Thus, a detailed study of regional population structures of $M$. tuberculosis and identification of the specific genotypes associated with drug resistance can facilitate both a more effective drug therapy regime and give information at the molecularepidemiological level.

A rapid determination of the resistance profile to antituberculosis drugs defines the choice of an effective drug therapy regime. Molecular genetic methods for determining drug resistance of mycobacteria require minimum time for completion of an analysis and are especially effective when access to a bacteriological laboratory is limited. However, the use of these methods requires detailed information on the molecular mechanisms for developing drug resistance and the spectrum of mutations causing resistance. The M. tuberculosis genome is exceptionally conserved with minimal horizontal transfer and an absence of plasmids $[9,10]$. The acquisition of resistance is due to mutations and deletions within the chromosome. These chromosomal changes affect protein-binding structures for the drug or the activity of enzymes that metabolize the drug. Mutations and deletions in intergenic regions of the genes $k a t G$, inhA, and $o x y R-a h p C$ are known to cause resistance to isoniazid. Resistance to rifampicin is most often caused by different mutations and deletions in the 81 bp catalyst region of the $r p o B$ gene that encodes the $\beta$ subunit of DNA-dependent RNA-polymerase. These aforementioned mutations are the principal modes of drug resistance in $M$. tuberculosis.

A persistent increase of tuberculosis cases has recently been noted in the Ukraine. In 2004 TB incidence rate was 81 per 100,000 in a population and a mortality rate was 23 per 100,000 in a population. In 2009 TB incidence and a mortality rates were slightly decreased to $73 / 100000$ and $18 / 100000$, respectively [11]. The reported incidence of drug-resistant isolates of $M$. tuberculosis is growing steadily; however, data on the genetic variation of isolates of $M$. tuberculosis circulating in northern Ukraine and on the spectrum and frequency of occurrence of mutations determining resistance to the principal anti-tuberculosis drugs isoniazid and rifampicin have not yet been reported. Here we report for the first time, molecular typing of isolates circulating in Kharkiv Oblast using VNTR- and RFLP-typing methods. We also identified mutations in genes associated with the development of resistance to rifampicin and isoniazid, determined their frequency, and found correlations between having a specific mutation and belonging to a certain mycobacterial genotype.

\section{Methods}

\section{Sampling}

A total of 98 consecutive observed adult smear-positive pulmonary TB patients presenting to the State Clinical Anti-Tuberculosis Dispensary (SC ATD) No. 1 and its regional branches in Kharkiv, between January and March 2004 were enrolled in the study. The State Clinical Anti-Tuberculosis Dispensary is the main referral center for TB in Kharkiv and captures the majority of TB cases in the city. Males aged between $20-60$ years (average age 40 years) dominated $(81 / 98,83 \%)$ the patient cohort. Smear - positive patients who had never been treated or were treated for less than 1 month were classified as new cases ( $\mathrm{n}=36,37 \%)$, designed as first group of examined patients. The remaining patients (n $=62,63 \%$ ) were classified as chronic cases that previously had active TB and considered clinically cured but had become smear-positive again, designed as second group of examined patients. The information collected included socioeconomic and demographic characteristics, current and previous history of M. tuberculosis infection, history of contact with a TB case, history of previous anti-tuberculosis treatment and chest $\mathrm{X}$ - ray findings. The most common form was infiltrative tuberculosis of the lungs in 61/98 (62\%) patients; fibrous-cavernous in 28/98 (29\%) patients; disseminated tuberculosis of the lungs in 6/98 (6\%) patients; caseous pneumonia in 2/98 (2\%) patients; and exudative pleuritis in $1 / 98(1 \%)$ patient. The study was approved by the Ethic Committee on Medical Research of the Institute of Chemical Biology and Fundamental Medicine SBRAS. Informed consent was obtained from all patients. There were no demographical or clinical differences between recruited patients and those who refused to participate. Bacteriological studies were performed at the Centralized Bacteriological Laboratory of SC ATD No.1, regularly fulfilling quality control. M. tuberculosis was grown for four weeks in Lowenstein-Jensen medium, before testing the isolates for sensitivity to isoniazid, rifampicin, streptomycin, ethambutol and kanamycin by the absolute concentration method [11].

\section{DNA isolation}

DNA was isolated from M. tuberculosis cultures as described by van Soolingen [12].

\section{VNTR-typing}

VNTR-typing of the loci; ETR A, B, C, MIRU2, MIRU4, MIRU10, MIRU16, MIRU20, MIRU23, MIRU24, MIRU26, MIRU27, MIRU31, MIRU39, and MIRU40 was performed by PCR with a final volume of $20 \mu \mathrm{L}$ containing; $65 \mathrm{mM}$ Tris- $\mathrm{HCl}$ (pH 8.9), $16 \mathrm{mM}\left(\mathrm{NH}_{4}\right)$ ${ }_{2} \mathrm{SO}_{4} ; 2.5 \mathrm{mM} \mathrm{MgCl}$, 0.05\% Tween 20, $0.2 \mathrm{mM}$ dNTP, $1 \mu \mathrm{M}$ of the appropriate oligonucleotide primers, 1 unit 
of Taq-DNA-polymerase, and 1-10 ng of $M$. tuberculosis genomic DNA. The oligonucleotide primer sequences are given in Table 1 . The reaction was carried out in an iCycler amplifier (Bio-Rad, USA) where after an initial denaturation step of $96^{\circ} \mathrm{C}$ for $3 \mathrm{~min}, 33$ cycles were performed as follows; denaturation at $95^{\circ} \mathrm{C}$ for $5 \mathrm{~s}$, annealing at $60^{\circ} \mathrm{C}$ for $10 \mathrm{~s}$, and elongation at $72^{\circ} \mathrm{C}$ for $20 \mathrm{~s}$.

The number of tandem repeat copies was calculated as a function of the size of the PCR product. The structure and number of repeat copies was also verified by direct sequencing of the amplified DNA fragments. The genotype of each isolate was expressed as a set of 15 digits where each digit of the 15-place number showed

Table 1 Oligonucleotide sequences of primers used

\begin{tabular}{|c|c|}
\hline Primer name & Nucleotide structure \\
\hline ETRA1 & 5'-GATTGAGGGGATCGTGATTGG-3' \\
\hline ETRA2 & 5'-CAGCTAGGCACTCCTGAGATTCC-3' \\
\hline ETRB1 & 5'-BGCGAACACCAGGACAGCATCATG \\
\hline ETRB2 & 5'-GGCATGCCGGTGATCGAGTGG \\
\hline ETRC1 & 5'-CCTTATGCTTTGCCTGTTTGACC-3' \\
\hline ETRC2 & 5'-TGTTCGGGGTGAGAAGATCG-3' \\
\hline MIRU02U & 5'-CAGGACACGGGTTCTACTG-3' \\
\hline MIRU02R & 5'-GGACTAGGTCGAGGTTGTGTC-3' \\
\hline MIRU04U & 5'-CAGGTCACAACGAGAGGAAGAGC \\
\hline MIRU04R & 5'-GCGGATCGGCCAGCGACTCCTC \\
\hline MIRU10U & 5'-GACTTCCAACAGCACCGTCTTATC-3' \\
\hline MIRU10R & 5'-TCGCACCGATCACGCTACG-3' \\
\hline MIRU16U & 5'-GTTGGAAACGGCGGTTATTGAC-3' \\
\hline MIRU16R & 5'-CGGAGTCGTCCAGCAAGACC-3' \\
\hline MIRU20U & 5'-TCGGAGAGATGCCCTTCGAGTTAG -3' \\
\hline MIRU2OR & 5'-TCACGGTCTCCGCACTAACG-3' \\
\hline MIRU23U & 5'-CTCACCAGGATCGCCAAACC-3' \\
\hline MIRU23R & 5'-TCTGACTCATGGTGTCCAACC-3' \\
\hline MIRU24U & 5'-GCTTGTGCGGGAAGGCTA-3' \\
\hline MIRU24R & 5'-CGATCGCGGATCTITGCT-3' \\
\hline MIRU26U & 5'-CCAGCAGTTGAGCACAGTTCG-3' \\
\hline MIRU26R & 5'-GGATAGGTCCGAGTTCGATTTCC-3' \\
\hline MIRU27U & 5'-CGGTGACCAACGTCAGATTC-3' \\
\hline MIRU27R & 5'-ACGTGACGGGGCATCTTC-3' \\
\hline MIRU31U & 5'-CCTTATGCTTTGCCTGTTTGACC-3' \\
\hline MIRU31R & 5'-TGTTCGGGGTGAGAAGATCG-3' \\
\hline MIRU39U & 5'-GTCAACAGACCACTAGACAAGCC-3' \\
\hline MIRU39R & 5'-GCAGCGTCCGTACTTCCG-3' \\
\hline MIRU40U & 5'-GCAAGAGCAAGAGCACCAAGC-3' \\
\hline MIRU40R & 5'-TGTCTAATCAGGTCTTTCTCTCACGC-3' \\
\hline MSPA & 5'-CGATCTGGTCGGCCCCGAAC-3' \\
\hline MSPB & 5'-TTCGTCGGGGTGTTCGTCCA-3' \\
\hline MUT531U & 5'-AAACCACAAGCGCCGAATGTC-3' \\
\hline MUT531R & 5'-TCTGATCGGCTCGCTGTC-3' \\
\hline RPOB1 & 5'-AACCGCCGCCTGCGTACGGT-3' \\
\hline
\end{tabular}

the number of copies of the corresponding tandem repeat.

\section{RFLP-typing}

RFLP-typing of $M$. tuberculosis DNA isolates was performed using the method described by van Soolingen and van Embden [12-14].

\section{Statistical analysis}

Statistical analysis was performed using the program Statistica 6.0 (Statsoft Inc.). Cluster analysis and construction of dendrograms was carried out using the UPGMA criterion (unweighted pair-group average) and the Neighbor-Joining method.

\section{Identification of mutations associated with the development of resistance to isoniazid and rifampicin} Primers were designed for amplification of fragments containing codon 315 of the rpoB gene (MspA and $\mathrm{MspB}$ ), and codon 531 of the rpoB gene (MUT531U and MUT531R). The primer sequences are given in Table 1. PCR amplification was performed in $20 \mu \mathrm{L}$ reaction volumes containing; $65 \mathrm{mM}$ Tris- $\mathrm{HCl}(\mathrm{pH} 8.9)$, $16 \mathrm{mM}\left(\mathrm{NH}_{4}\right)_{2} \mathrm{SO}_{4}, 0.05 \%$ Tween $20,2.5 \mathrm{mM} \mathrm{MgCl}_{2}$, $100 \mu \mathrm{M}$ dNTP, $1 \mu \mathrm{M}$ primers, 1 unit of Taq-DNA-polymerase, and 1-10 ng of $M$. tuberculosis genomic DNA. The reaction was carried out in a Tertsik amplifier (DNA-technology, Russia) with an initial denaturation step of $96^{\circ} \mathrm{C}$ for $3 \mathrm{~min}$, followed by 38 cycles consisting of: denaturation at $95^{\circ} \mathrm{C}$ for $10 \mathrm{~s}$, annealing at $68^{\circ} \mathrm{C}$ for $10 \mathrm{~s}$ (for the fragment of $\mathrm{katG}$ ), or at $55^{\circ} \mathrm{C}$ for $10 \mathrm{~s}$ (for the fragment of $r p o B$ ), and elongation at $72^{\circ} \mathrm{C}$ for $20 \mathrm{~s}$. The presence of an amplification product was checked by electrophoresis in 6\% PAAG with subsequent visualization of the DNA by ethidium bromide staining.

A mutation in codon 315 of the katG gene was determined by hydrolyzing $10 \mu \mathrm{L}$ of the amplification product using the enzyme MspI. The total reaction volume was $15 \mu \mathrm{L}$. One unit of enzyme was added twice at 1 hour intervals and the mixture was incubated at $37^{\circ} \mathrm{C}$. The restriction mixture was analyzed by electrophoresis in $8 \%$ PAAG. Fragments of 72 bp, 57 bp, and 6 bp corresponded to the wild-type allele of katG; whilst fragments of $72 \mathrm{bp}, 36 \mathrm{bp}, 21 \mathrm{bp}$, and $6 \mathrm{bp}$ corresponded to mutations in codon 315 of $k a t G$.

The amplification product from rpoB was hydrolyzed by endonuclease restriction using the enzyme BstPAI in order to determine whether a mutation in codon 531 of gene was present. In case where a wild-type allele was present in the amplified DNA fragment, a substitution was inserted into one of the oligonucleotide primers to create a recognition site for the endonuclease. The hydrolysis was carried out in a $25 \mu \mathrm{L}$ reaction volume using $20 \mu \mathrm{L}$ of the amplification product and 2 units of 
BstPAI. The reactions were incubated at $65^{\circ} \mathrm{C}$ for 2 hours and the restriction products analyzed by electrophoresis in $8 \%$ PAAG with subsequent visualization of the DNA by ethidium bromide staining. Fragments of $153 \mathrm{bp}$ corresponded to the mutant-type allele; fragments of $135 \mathrm{bp}$ and $18 \mathrm{bp}$ to a wild-type allele. Direct sequencing of the catalyst region of the $r p o B$ gene was performed on an ABI 3130XL Genetic Analyzer automated sequencer (Applied Biosystems, USA) using the Big dye 3.1 set and primers RPOB1 and MUT531R (see Table 1).

\section{Results}

\section{VNTR-typing}

VNTR-typing using 15 polymorphic loci of the $98 \mathrm{M}$. tuberculosis isolates identified 75 genetic types. A total of 67 isolates had unique profiles. The remaining 31 isolates formed clusters of different sizes (with a difference coefficient $<0.125)$. The Hunter-Gaston discrimination index (HGDI) for this method was 0.985 . A clustering dendrogram of $M$. tuberculosis isolates obtained from tuberculosis patients in Kharkiv Oblast (Figure 1) was constructed using the UPGMA and N-J methods based on the VNTR-typing and shows three large branches. These branches consist of smaller clusters or in most instances, include isolates with unique allele profiles.
The Beijing strain family is represented in this study by 32 isolates (32\%). Within the Beijing strain family isolates, the majority 10 (31.5\%) had the genetic profile 233325153533424 (for typing over 12 MIRU-loci and three ETRA, B, C-loci). The remaining isolates of belonging to this family had either a unique profile or fell into small clusters of 3-5 isolates.

Representatives of the LAM isolates family formed a large cluster of 23 isolates (23\%). Of these, 5 isolates had the allelic profile 134325153225222, and 2 isolates 134325113225222. The others isolates of LAM families had unique profiles.

The Haarlem strain family was represented by 7 isolates $(7 \%)$, two isolates had the same genetic profile, 235325153323323; but the allelic profiles of the other five isolates were unique.

We were unable to assign 36 isolates to any previously known families. A small cluster was formed by 4 (4\%) of the isolates but the remaining 32 (32\%) had a unique genetic profiles.

Isolates of the Beijing strain family were most common among the first group of examined patients (31\%), followed by isolates of the LAM strain family (14\%), and finally isolates of the Haarlem strain family (8\%). In the second group isolates of the Beijing and LAM strain families represented $39 \%$ and $29 \%$ of all isolates,

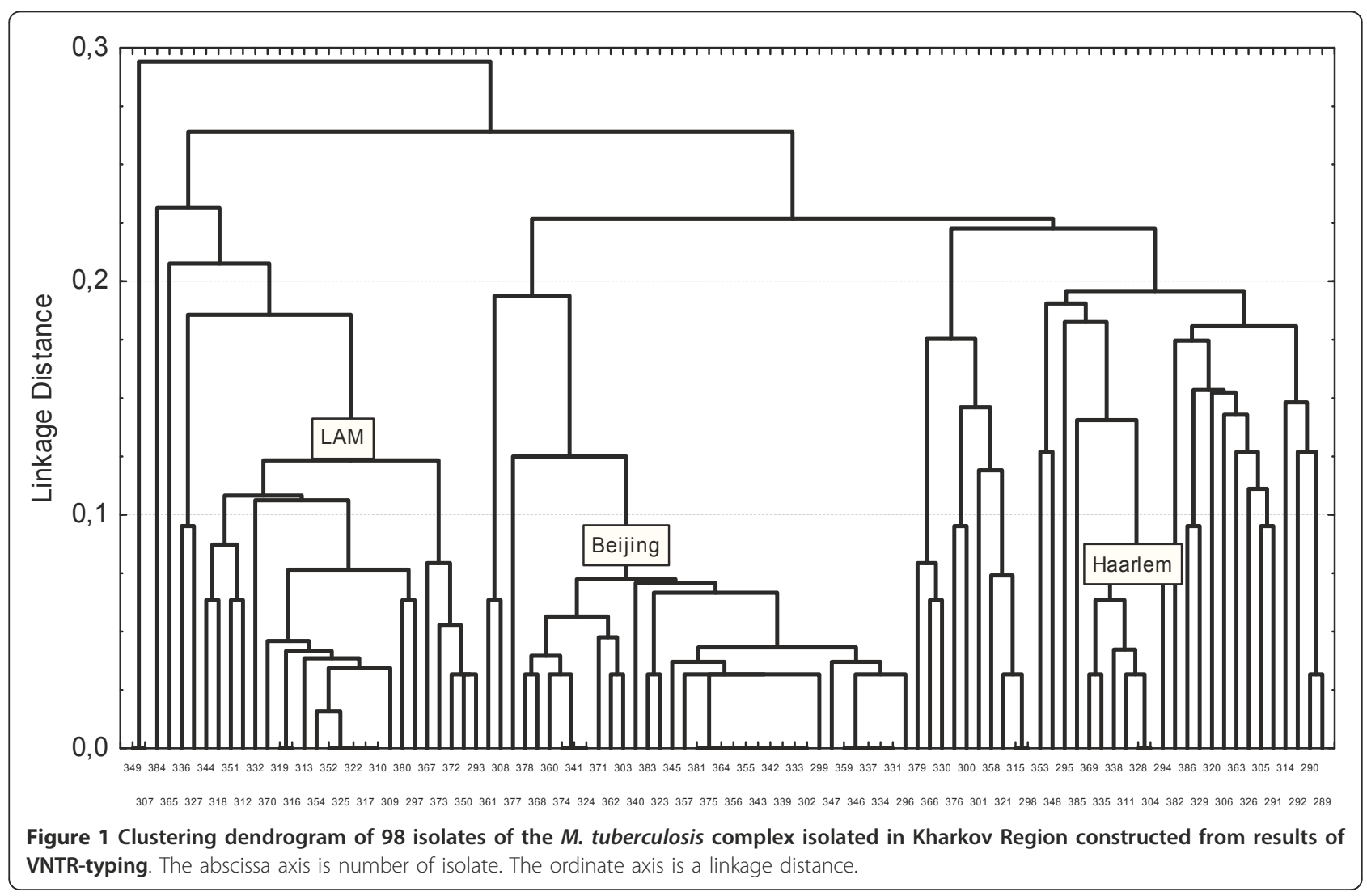


respectively. The increase in the number of isolates from the Beijing and LAM strain families was not statistically significant $\left(\chi^{2}=0.33, \mathrm{p}=0.56 ; \chi^{2}=2.08, \mathrm{p}=0.15\right.$, respectively).

\section{RFLP-typing}

A total of 31 isolates with sufficient DNA for analysis were typed using the RFLP-IS6110 method for a more accurate characterization. A schematic representation of the results is shown in Figure 2. The 31 isolates were represented by 23 different genetic profiles using RFLP-
IS6110 typing versus 26 profiles obtained from VNTRtyping of the same samples. A clustering dendrogram for these isolates was constructed based on the results of the IS6110-RFLP-typing (Figure 2). Two large clusters with a mutual difference coefficient of $<0.225$ are visible on the dendrogram. The clustering was $29 \%$.

The 9 isolates of the Beijing strain family made up a very large and rather homogeneous group (figure 2, lanes 381 to 303) and had between 14 and 19 copies of the IS6110 element. We identified several variants of the Beijing strain family; 2 isolates for variant B; 6 isolates
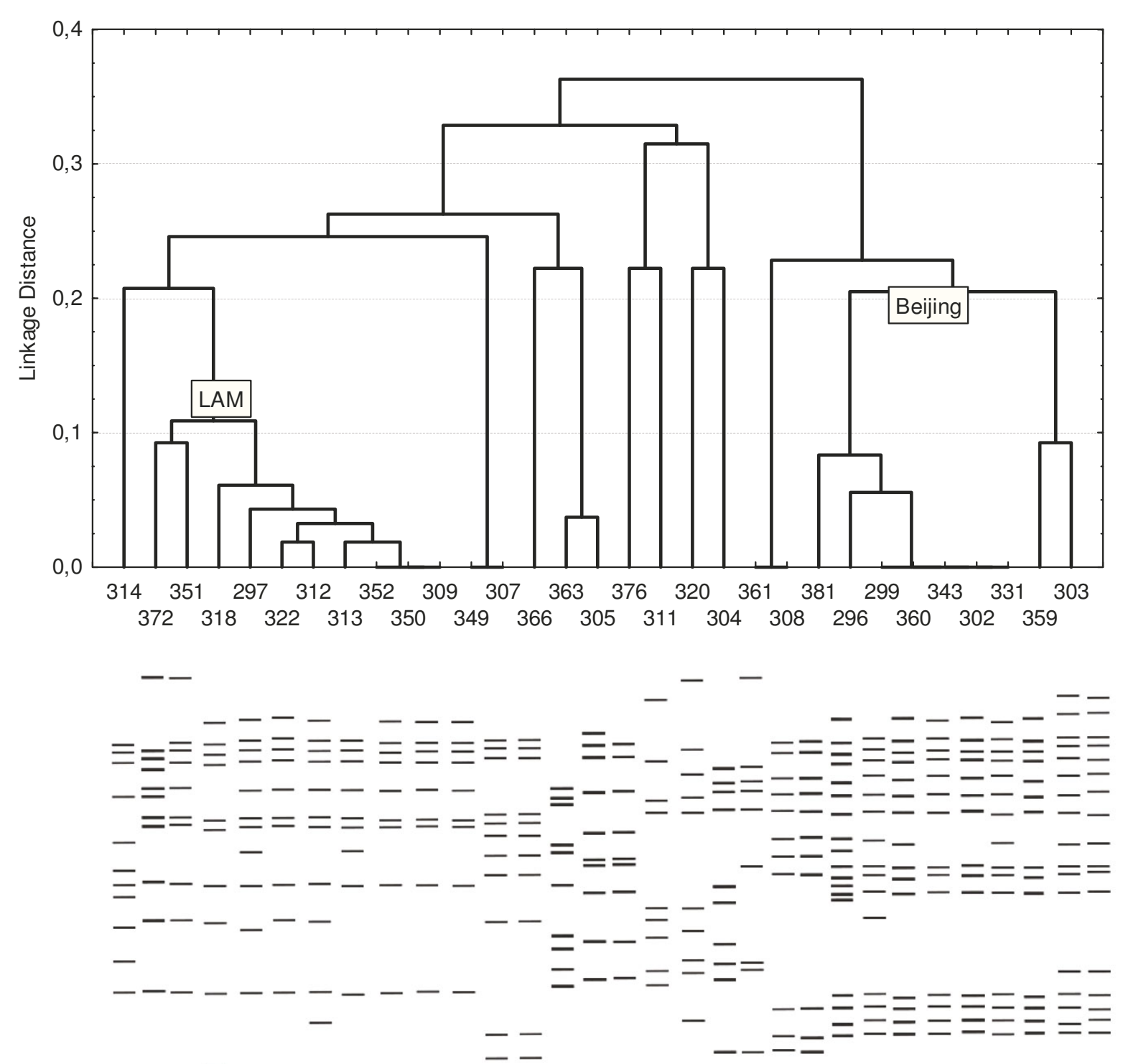

Figure 2 Clustering dendrogram of 31 isolates from M. tuberculosis constructed from results of IS6110-RFLP-typing. Tracks 381, 296, 299, 360, 343, 302, 331 are isolates belonging to the Beijing strain family; tracks 372, 351, 318, 297, 322, 312, 313, 352, 350, 309, are isolates belonging to the LAM strain family. The abscissa axis is number of isolate. The ordinate axis is a linkage distance. Simulation of RFLP-typing of these samples appears below. 
for variant $\mathrm{A}$, and 1 isolate for variant $\mathrm{C}$ [15]. All 9 isolates had a characteristic VNTR-profile of Beijing family. A heterogeneous group (Figure 2, lanes 372 to 309) with a difference coefficient $<0.1$, that included isolates of the LAM strain family and made up 30\% (10 samples) was also seen. The presence of 10 to 12 copies of IS6110 was characteristic of this family. VNTR-typing confirmed that these isolates belong to the LAM family. Two isolates (Figure 2, lanes 307 and 349) had the same RFLP- and VNTR-profile and formed a cluster. Three isolates (Figure 2, lanes 320, 311 and 304) had same RFLP-profiles, but only two isolates (№№311,304) were assigned according to the Haarlem strain family based on VNTR-typing. Isolates № 361 and №308 had identical RFLP-profiles and possessed by VNTR types. The remaining 5 isolates (30\%) were found to have the unique RFLP- and VNTR-profiles.

A clustering dendrogram of these same isolates was also constructed based on VNTR-typing of these isolates (Figure 3). The difference coefficients for the LAM and Beijing strain families were $<0.1$ and $<0.125$ respectively. We computed the Hunter-Gaston discrimination indices for both methods: for RFLP-typing, it was 0.97; for VNTR-typing, 0.987. This indicated that VNTR-typing using 15 loci had a higher resolving capability.

Here the perfect concordance between two highly discriminatory molecular methods was observed. Rand coefficient commonly used for comparing congruence of typing methods was 0.963 [16].

\section{Analysis of drug resistance}

All isolates were tested using the absolute concentration method for resistance to isoniazid, rifampicin, streptomycin, kanamycin and ethambutol. Monoresistant tuberculosis was observed in 14/98 (14\%) patients and polyresistant, in $60 / 98$ (61\%). It was found that $58 \%$ (57/98) of the isolates were resistant to isoniazid, $49 \%$ (48/98) to rifampicin, $75 \%$ (74/98) to streptomycin, 40\% (39/98) to kanamycin and $35 \%$ (34/98) to ethambutol. MDR-TB (resistance to isoniazid and rifampicin, both) was seen in 48/98 (49\%) isolates [17]. Resistance to all tested drugs was seen in 30/98 (30\%) isolates. Twenty four isolates $(25 \%)$ were sensitive to all drugs tested.

\section{Determination of mutations associated with resistance to rifampicin and isoniazid}

PCR-RFLP analysis showed that 35 isolates (73\%) that were resistant to rifampicin had the codon substitution Ser531Leu in rpoB. Sequencing of an 81 bp region of rрoB was performed for 13 rifampicin-resistant isolates with no mutation present at codon 531 of the gene (Tables 2). Codon substitutions were identified in five locations; in 6 isolates $(12.5 \%)$ codon 526 changed from His $\rightarrow$ Tyr, in 4 insolates (8\%), codon 516 changed from $\mathrm{Asp} \rightarrow \mathrm{Val}$, and in 2 isolates (4\%), codon 533 changed from Leu $\rightarrow$ Pro. In 1 isolate (2\%), two mutations were observed simultaneously in codons 509 and 511 with changes from Ser $\rightarrow$ Thr and Leu $\rightarrow$ Pro respectively. The sensitivity and specificity of the genetic analysis was $100 \%$.

Screening of the $M$. tuberculosis isolates for the presence of a mutation in codon 315 of the kat $G$ gene showed that $53 / 57$ (93\%) isoniazid-resistant isolates carried this mutation. Four isoniazid- sensitive isolates also had the Ser315Thr substitution. Repeated analysis of these isolates using DNA sequencing of the corresponding part of the

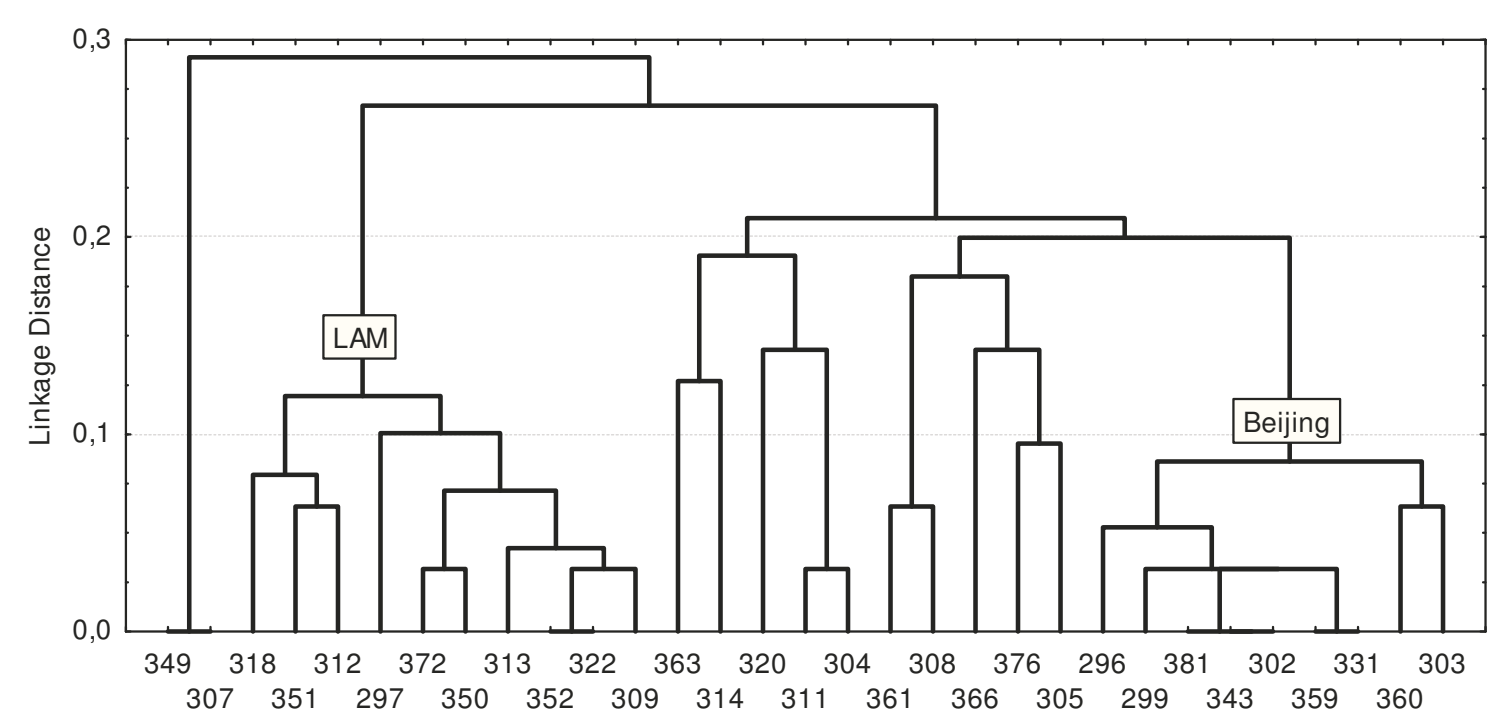

Figure $\mathbf{3}$ Clustering dendrogram of $\mathbf{3 1}$ isolates from $\mathbf{M}$. tuberculosis constructed from results of VNTR-typing. The abscissa axis is number of isolate. The ordinate axis is a linkage distance. 
Table 2 Codon substations other than Ser531Leu found when sequencing the $r p o B$ gene from isolates resistant to rifampicin

\begin{tabular}{|c|c|}
\hline Strain No. & Codon, substitution \\
\hline & 509 AGC $\rightarrow$ ACC, Ser $\rightarrow$ Thr \\
\hline 337 & $511 \mathrm{CTG} \rightarrow$ CCG, Leu $\rightarrow$ Pro \\
\hline 380 & $516 \mathrm{GAC} \rightarrow \mathrm{GTC}, \mathrm{Asp} \rightarrow \mathrm{Val}$ \\
\hline 372 & $516 \mathrm{GAC} \rightarrow \mathrm{GTC}, \mathrm{Asp} \rightarrow \mathrm{Val}$ \\
\hline 319 & $516 \mathrm{GAC} \rightarrow \mathrm{GTC}, \mathrm{Asp} \rightarrow \mathrm{Val}$ \\
\hline 367 & $516 \mathrm{GAC} \rightarrow \mathrm{GTC}, \mathrm{Asp} \rightarrow \mathrm{Val}$ \\
\hline 358 & $526 \mathrm{CAC}-\rightarrow$ CTC, His $\rightarrow$ Leu \\
\hline 378 & $526 \mathrm{CAC} \rightarrow \mathrm{CT}$, His $\rightarrow$ Leu \\
\hline 374 & $526 \mathrm{CAC} \rightarrow \mathrm{TAC}, \mathrm{His} \rightarrow \mathrm{Tyr}$ \\
\hline 322 & $526 \mathrm{CAC} \rightarrow \mathrm{TAC}, \mathrm{His} \rightarrow \mathrm{Tyr}$ \\
\hline 379 & $526 \mathrm{CAC} \rightarrow \mathrm{TAC}, \mathrm{His} \rightarrow \mathrm{Tyr}$ \\
\hline 290 & $526 \mathrm{CAC} \rightarrow \mathrm{TAC}, \mathrm{His} \rightarrow \mathrm{Tyr}$ \\
\hline 368 & $533 \mathrm{CTG} \rightarrow \mathrm{CCG}$, Leu $\rightarrow$ Pro \\
\hline 301 & $533 \mathrm{CTG} \rightarrow \mathrm{CCG}, \mathrm{Leu} \rightarrow$ Pro \\
\hline
\end{tabular}

gene confirmed that a mutation was present in this codon. This may indicate that the results of the bacteriological study were flawed. The sensitivity and specificity of the genetic analysis for resistance to isoniazid was 93\% and $90 \%$, respectively. Our findings in this study agree with reports in the literature where the phenotype test for determining sensitivity to isoniazid has also been shown to be unreliable (92\%) [18,19].

\section{Analysis of the correlation between multiple drug resistance and genotype of the isolates}

The frequency and spectrum of drug resistance of the isolates belonging to the different strain families were analyzed (Table 3). Belonging to the LAM strain family and having multiple drug resistance was shown to be associated using the Spearman correlation coefficient ( $R$ $=0.27, \mathrm{p}=0.0059)$. Such an association was not found for the Beijing strain family $(\mathrm{R}=0.1, \mathrm{p}=0.3241)$.

\section{Discussion}

Mutations in the catalyst region of the $r p o B$ gene are associated with the development of resistance to rifampicin. In $86 \%$ of occurrences, they arise at codons 531, 526 , or 516 . These mutations in certain regions of
Russia are responsible for almost all rifampicin-resistant isolates [20]. In our collection of isolates, mutations at these codons were identified in $94 \%$ of the rifampicinresistant isolates, which is similar to other reported results [14] and reflects the geographical similarity of these regions. The number of rifampicin-resistant isolates with mutations at codons 531, 526, and 516 of the rpoB gene $(73 \%, 12.55 \%$ and $8 \%$ respectively) agreed with those found by Nikolaevskyy et al. during typing of isolates from Nikolaev and Odessa, Ukraine [21]. These results are typical of countries with an average or high level of resistance to rifampicin and predominance of isolates belonging to the Beijing strain family [22].

The occurrence of the nucleotide substitution $\mathrm{AGC} \rightarrow \mathrm{ACC}$ at codon 315 of the $k a t G$ gene in isoniazidresistant isolates correlated well with the phenotype test (93\%). Similar results have been obtained for northwest Russia (93.6\%), Latvia (91.0\%), and Lithuania (85.7\%) [22-24]. It is noteworthy that the aforementioned mutation according to the literature has an insignificant effect on decreasing bacterial adaptation and is very often encountered in rifampicin-resistant strains $[23,25,26]$. It is necessary to note, a considerable quantity isolates $(30 / 98,30 \%)$ were resistant to all tested drugs, however we were not able to designate these isolates as XDR due to lack of fluorquinolones resistance data $[27,28]$.

Genotyping of 15 polymorphic loci showed a large variation in the genetic profiles of the studied isolates. The high discrimination level of VNTR-typing using 15 polymorphic loci $(\mathrm{HGDI}=0.985)$ resulted in a significant percentage of isolates (36\%) belonging to as yet unidentified strain families of $M$. tuberculosis or having individual non-clustering genotypes. Six loci (MIRU10, MIRU26, MIRU31, MIRU39, MIRU40 and ETRA) had a discrimination index $>0.5$. The number of allele repeats varied from 3 to 9 , confirming their high discriminating capability [29]. The discovery of a large cluster of isolates belonging to the Beijing strain family with numerous branches on the clustering dendrogram indicates that these isolates are widely distributed and have circulated in this region for a long time. The frequency of occurrence of this strain family was $34 \%$, which is below the frequency of occurrence of isolates of this strain family for the Russian Federation (about 50\%) [30,31].

Table 3 Analysis of drug resistance of isolates belonging to different strain families of $M$. tuberculosis

\begin{tabular}{|c|c|c|c|c|c|c|c|c|c|}
\hline & Total & Beijing & $\%$ & LAM & $\%$ & Haarlem & $\%$ & Others & $\%$ \\
\hline Total & 98 & 31 & 32 & 16 & 16 & 7 & 7 & 44 & 45 \\
\hline Sens. to all AT drugs & 22 & 6 & 27 & 4 & 18 & 1 & 5 & 11 & 50 \\
\hline Resistant to 1-4 AT drugs & 76 & 25 & 33 & 12 & 16 & 6 & 8 & 33 & 43 \\
\hline MDR & 48 & 17 & 35 & 11 & 23 & 1 & 2 & 19 & 40 \\
\hline
\end{tabular}

AT = anti-tuberculosis, MDR = multiple drug resistance 
The frequency of occurrence of $M$. tuberculosis isolates from the LAM strain family (23\%) in Kharkiv Oblast was comparable with that found for Bulgaria (22\%) [32] and Kaliningrad Oblast of Russia (18\%) [33]. However, isolates from this strain family in the Urals and western Siberian regions of Russia were only 9-10\% [31,34]. We observed that just $7 \%$ of our isolates were from the Haarlem strain family, which has European origins. The frequency of occurrence of this family is higher in European countries and in an analogous study in Scandinavia the distribution of isolates from the Haarlem strain family was $20 \%$ [35]. The following migration patterns for the various strain families of $M$. tuberculosis can be proposed: strains from the Beijing family were distributed into Ukraine from eastern Russia; whilst strains from the LAM and Haarlem families, came from the European side.

We demonstrated an association between belonging to the LAM strain family and having multidrug resistance (MDR). At the same time such association had not been found for the Beijing strain family. Previously, not only the predominance of the Beijing strain family but also a statistically significant association for this family with MDR (89 of 225 isolates belonging to the Beijing family; of these $48.3 \%$ had MDR, $19.8 \%$ did not; RR 2.43 , 95\% CI 1.63-3.63) was described during a study of isolates from M. tuberculosis circulating in Odessa and Nikolaev (Ukraine) [21]. Moreover, the previous study showed that isolates with the genetic profile 223325173533424 and the Beijing strain family subtype had more mutations associated with rifampicin and isoniazid resistance than those from other subtypes of this family (RR 1.86, 95\% CI 1.41-2.47 and RR 1.74, 95\% CI 1.17-2.57, for isoniazid and rifampicin resistance, respectively). Drobniewski et al. showed during typing of $M$. tuberculosis circulating in Russia that this genotype was frequently encountered among prisoners [36]. In our study we didn't find isolates with such genetic profile (223325173533424). Isolates with the genetic profile (233325153533424) make up $31.5 \%$ of all isolates from the Beijing isolates family in our setting. However, reliable differences between other Beijing isolates family subtypes with respect to the predominance of mutations related to isoniazid and rifampicin resistance were not found $\left(\chi^{2}=1.035, \mathrm{p}=0.3 ; \chi^{2}=0.68\right.$, $\mathrm{p}=0.4$, respectively).

We did not find a correlation between having a substitution at codon 315 of the kat $G$ gene and belonging to the Beijing or LAM strain family $(\mathrm{R}=0.14, \mathrm{P}=0.17, \mathrm{R}$ $=0.08, \mathrm{P}=0.44$, respectively). However, a correlation was found between having a mutation at codon 531 of the $r p o B$ gene and belonging to the Beijing strain family $(\mathrm{R}=-0.2, \mathrm{P}=0.04)$. This correlation was not found for the LAM strain family $(\mathrm{R}=0.19, \mathrm{P}=0.06)$. It is interesting to note that according to the literature the presence of such associations depends on the geographic region because an association between belonging to the Beijing strain family and having a mutation at codon 531 of the $r p o B$ gene was not found in eastern Asia [37]. This association is encountered in northwestern Russia but in northern Africa is more often found in isolates belonging to the Beijing strain family than in those of non-Beijing strain families [30,38]. An association was also found between having a substitution at codon 315 of the katG gene and belonging to the Beijing strain family in studies carried out in Russia and Kazakhstan [30,39].

A study of $M$. tuberculosis genotypes in patients with newly acquired tuberculosis and chronic tuberculosis is very important for the epidemiological analysis of genotype distribution in a specific region. We found a percentage increase of the Beijing and LAM isolates in the second group of patients at comparison with the first ones. However, it was not statistically significant $\left(\chi^{2}=\right.$ $0.33, \mathrm{p}=0.56 ; \chi^{2}=2.08, \mathrm{p}=0.15$, respectively). This may indicate that these strain families of $M$. tuberculosis are transmitted to an equal extent.

\section{Conclusions}

Here we have characterized for the first time, the genetic variation of $M$. tuberculosis isolates circulating in northeastern Ukraine and determined the frequency of occurrence of mutations associated with the development of resistance to isoniazid and rifampicin. Associations between MDR of the isolate and belonging to the LAM strain family and between belonging to the Beijing strain family and having a mutation at codon 531 of the rроB gene were demonstrated. Representatives of the LAM strain family were genetically heterogeneous in the studied isolates, which is inconsistent with recent transmission and has high epidemiological significance for this region. Unfortunately, this particular study was rather small and the high percent of secondary cases could bias real population structure of Mycobacterium tuberculosis complex strains from Ukraine. We suggest that further DNA fingerprinting studies involving better characterized prime and secondary TB cases obtained more recently will be useful. The discovery of the principal phylogenetic families of $M$. tuberculosis and the description of their properties, especially drug resistance, will help the selection of more effective preventative measures in the fight against tuberculosis in the complicated epidemic situation in Ukraine.

\section{Acknowledgements}

We thank the staff of the State Clinical Anti-Tuberculosis Dispensary (SC ATD) for their support. We are particularly grateful to the bacteriologists, physicians, and nurses as well as the patients who took part in the study. 


\section{Author details}

IInstitute of Chemical Biology and Basic Medicine, Siberian Branch, Russian Academy of Sciences, Novosibirsk, Russian Federation, Russia. ${ }^{2}$ Kharkiv Medical Academy of Graduate Education, Kharkiv, Ukraine.

\section{Authors' contributions}

MAD carried out the molecular genetic studies, drafted the manuscript, and performed the statistical analysis. AAL, PIP, VSK participated in acquisition of sample collection. EAK participated in the sequence alignment. MLF conceived of the study, and participated in its design and coordination. All authors read and approved the final manuscript.

\section{Competing interests}

The authors declare that they have no competing interests.

Received: 22 July 2010 Accepted: 28 March 2011

Published: 28 March 2011

\section{References}

1. Matteelli A, Migliori GB, Cirillo D, Centis R, Girard E, Raviglione M: Multidrug-resistant and extensively drug-resistant Mycobacterium tuberculosis: epidemiology and control. Expert review of anti-infective therapy 2007, 5(5):857-871.

2. Gagneux S, Small PM: Global phylogeography of Mycobacterium tuberculosis and implications for tuberculosis product development. Lancet Infect Dis 2007, 7(5):328-337.

3. Glynn JR, Whiteley J, Bifani PJ, Kremer K, van Soolingen D: Worldwide occurrence of Beijing/W strains of Mycobacterium tuberculosis: a systematic review. Emerg Infect Dis 2002, 8(8):843-849.

4. Malik AN, Godfrey-Faussett P: Effects of genetic variability of Mycobacterium tuberculosis strains on the presentation of disease. Lancet Infect Dis 2005, 5(3):174-183.

5. Lopez B, Aguilar D, Orozco H, Burger M, Espitia C, Ritacco V, Barrera L, Kremer K, Hernandez-Pando R, Huygen K, et al: A marked difference in pathogenesis and immune response induced by different Mycobacterium tuberculosis genotypes. Clin Exp Immunol 2003, 133(1):30-37.

6. Cox HS, Kubica T, Doshetov D, Kebede Y, Rusch-Gerdess S, Niemann S: The Beijing genotype and drug resistant tuberculosis in the Aral Sea region of Central Asia. Respir Res 2005, 6:134

7. Ramazanzadeh R, Farnia P, Amirmozafari N, Ghazi F, Ghadertotonchi Z, Kamran J, Mohammadi F, Mirsaedi M, Masjedi M: Comparison between molecular epidemiology, geographical regions and drug resistance in Mycobacterium tuberculosis strains isolated from Iranian and Afghan patients. Chemotherapy 2006, 52(6):316-320.

8. Shemyakin IG, Stepanshina VN, Ivanov IY, Lipin MY, Anisimova VA Onasenko AG, Korobova OV, Shinnick TM: Characterization of drugresistant isolates of Mycobacterium tuberculosis derived from Russian inmates. Int J Tuberc Lung Dis 2004, 8(10):1194-1203.

9. Filliol I, Motiwala AS, Cavatore M, Qi W, Hazbon MH, Bobadilla del Valle M, Fyfe J, Garcia-Garcia L, Rastogi N, Sola C, et al: Global phylogeny of Mycobacterium tuberculosis based on single nucleotide polymorphism (SNP) analysis: insights into tuberculosis evolution, phylogenetic accuracy of other DNA fingerprinting systems, and recommendations for a minimal standard SNP set. J Bacteriol 2006, 188(2):759-772

10. Gutacker MM, Mathema B, Soini H, Shashkina E, Kreiswirth BN, Graviss EA, Musser JM: Single-nucleotide polymorphism-based population genetic analysis of Mycobacterium tuberculosis strains from 4 geographic sites. J Infect Dis 2006, 193(1):121-128.

11. Drobniewski FA, Wilson SM: The rapid diagnosis of isoniazid and rifampicin resistance in Mycobacterium tuberculosis-a molecular story. Journal of medical microbiology 1998, 47(3):189-196.

12. van Soolingen D, Borgdorff MW, de Haas PE, Sebek MM, Veen J, Dessens M, Kremer K, van Embden JD: Molecular epidemiology of tuberculosis in the Netherlands: a nationwide study from 1993 through 1997. J Infect Dis 1999, 180(3):726-736

13. van Embden JD, Cave MD, Crawford JT, Dale JW, Eisenach KD, Gicquel B, Hermans P, Martin C, McAdam R, Shinnick TM, et al: Strain identification of Mycobacterium tuberculosis by DNA fingerprinting: recommendations for a standardized methodology. J Clin Microbiol 1993, 31(2):406-409.
14. Van Soolingen D: Molecular epidemiology of tuberculosis and other mycobacterial infections: main methodologies and achievements. J Intern Med 2001, 249(1):1-26.

15. Bifani PJ, Mathema B, Kurepina NE, Kreiswirth BN: Global dissemination of the Mycobacterium tuberculosis W-Beijing family strains. Trends Microbiol 2002, 10(1):45-52.

16. Rand WM: Objective criteria for the evaluation of clustering methods. Journal of the American Statistical Association 1971, 66(336):846-850.

17. Ramaswamy S, Musser JM: Molecular genetic basis of antimicrobial agent resistance in Mycobacterium tuberculosis: 1998 update. Tuber Lung Dis 1998, 79(1):3-29.

18. Voronina EN, Vikhrova MA, Khrapov EA, Kinsht VN, Norkina OV, Gorbunova EV, Shabaldin AV, Glushkov AN, Krasnov VA, Filipenko ML: KatG Ser3 15Thr mutation as the main reason of isoniazid resistance in Mycobacterium tuberculosis isolated in the Novosibirsk and Kemerovo Regions. Mol Gen Mikrobiol Virusol 2004, 3: 8-11.

19. Telenti A, Honore N, Bernasconi C, March J, Ortega A, Heym B, Takiff HE, Cole ST: Genotypic assessment of isoniazid and rifampin resistance in Mycobacterium tuberculosis: a blind study at reference laboratory level. Journal of clinical microbiology 1997, 35(3):719-723.

20. Mokrousov I, Otten T, Vyshnevskiy B, Narvskaya O: Allele-specific rpoB PCR assays for detection of rifampin-resistant Mycobacterium tuberculosis in sputum smears. Antimicrob Agents Chemother 2003, 47(7):2231-2235

21. Nikolayevskyy W, Brown TJ, Bazhora Yl, Asmolov AA, Balabanova YM, Drobniewski FA: Molecular epidemiology and prevalence of mutations conferring rifampicin and isoniazid resistance in Mycobacterium tuberculosis strains from the southern Ukraine. Clin Microbiol Infect 2007, 13(2):129-138

22. Tracevska T, Jansone I, Broka L, Marga O, Baumanis V: Mutations in the rpoB and katG genes leading to drug resistance in Mycobacterium tuberculosis in Latvia. J Clin Microbio/ 2002, 40(10):3789-3792.

23. Bakonyte D, Baranauskaite A, Cicenaite J, Sosnovskaja A, Stakenas P: Molecular characterization of isoniazid-resistant Mycobacterium tuberculosis clinical isolates in Lithuania. Antimicrob Agents Chemother 2003, 47(6):2009-2011.

24. Mokrousov I, Narvskaya O, Otten T, Limeschenko E, Steklova L, Vyshnevskiy B: High prevalence of KatG Ser315Thr substitution among isoniazid-resistant Mycobacterium tuberculosis clinical isolates from northwestern Russia, 1996 to 2001. Antimicrob Agents Chemother 2002, 46(5):1417-1424

25. Pym AS, Saint-Joanis B, Cole ST: Effect of katG mutations on the virulence of Mycobacterium tuberculosis and the implication for transmission in humans. Infect Immun 2002, 70(9):4955-4960.

26. van Soolingen $D$, de Haas $P E$, van Doorn $H R$, Kuijper $E$, Rinder $H$, Borgdorff MW: Mutations at amino acid position 315 of the katG gene are associated with high-level resistance to isoniazid, other drug resistance, and successful transmission of Mycobacterium tuberculosis in the Netherlands. J Infect Dis 2000, 182(6):1788-1790.

27. Extensively drug-resistant tuberculosis (XDR-TB): recommendations for prevention and control. Releve epidemiologique hebdomadaire/Section d'hygiene du Secretariat de la Societe des Nations = Weekly epidemiological record/Health Section of the Secretariat of the League of Nations 2006, 81(45):430-432.

28. Plan to combat extensively drug-resistant tuberculosis: recommendations of the Federal Tuberculosis Task Force. MMWR Recomm Rep 2009, 58(RR-3):1-43.

29. Sola C, Filliol I, Legrand E, Lesjean S, Locht C, Supply P, Rastogi N: Genotyping of the Mycobacterium tuberculosis complex using MIRUs: association with VNTR and spoligotyping for molecular epidemiology and evolutionary genetics. Infect Genet Evol 2003, 3(2):125-133.

30. Mokrousov I, Otten T, Vyazovaya A, Limeschenko E, Filipenko ML, Sola C, Rastogi N, Steklova L, Vyshnevskiy B, Narvskaya O: PCR-based methodology for detecting multidrug-resistant strains of Mycobacterium tuberculosis Beijing family circulating in Russia. Eur J Clin Microbiol Infect Dis 2003, 22(6):342-348

31. Norkina OV, Kinsht VN, Mokrousov IV, Kurunov lu N, Krasnov VA Filipenko ML: The genetic diversity of Mycobacterium tuberculosis and an assessment of risk factors of tuberculosis spread in Russia's Siberian region by molecular epidemiological methods. Mol Gen Mikrobiol Virusol 2003, 3: 9-18. 
32. Valcheva V, Mokrousov I, Rastogi N, Narvskaya O, Markova N: Molecular characterization of Mycobacterium tuberculosis isolates from different regions of Bulgaria. J Clin Microbiol 2008, 46(3):1014-1018.

33. Mokrousov I, Otten T, Zozio T, Turkin E, Nazemtseva V, Sheremet A, Vishnevsky B, Narvskaya O, Rastogi N: At Baltic crossroads: a molecular snapshot of Mycobacterium tuberculosis population diversity in Kaliningrad, Russia. FEMS Immunol Med Microbiol 2009, 55(1):13-22.

34. Kovalev SY, Kamaev EY, Kravchenko MA, Kurepina NE, Skorniakov SN: Genetic analysis of mycobacterium tuberculosis strains isolated in Ural region, Russian Federation, by MIRU-VNTR genotyping. Int J Tuberc Lung Dis 2005, 9(7):746-752.

35. Brudey K, Gordon M, Mostrom P, Svensson L, Jonsson B, Sola C, Ridell M, Rastogi N: Molecular epidemiology of Mycobacterium tuberculosis in western Sweden. J Clin Microbiol 2004, 42(7):3046-3051.

36. Drobniewski F, Balabanova Y, Nikolayevsky V, Ruddy M, Kuznetzov S, Zakharova S, Melentyev A, Fedorin I: Drug-resistant tuberculosis, clinical virulence, and the dominance of the Beijing strain family in Russia. Jama 2005, 293(22):2726-2731.

37. Qian L, Abe C, Lin TP, Yu MC, Cho SN, Wang S, Douglas JT: rpoB genotypes of Mycobacterium tuberculosis Beijing family isolates from East Asian countries. J Clin Microbiol 2002, 40(3):1091-1094

38. Van Rie A, Warren R, Mshanga I, Jordaan AM, van der Spuy GD, Richardson M, Simpson J, Gie RP, Enarson DA, Beyers N, et al: Analysis for a limited number of gene codons can predict drug resistance of Mycobacterium tuberculosis in a high-incidence community. J Clin Microbiol 2001, 39(2):636-641

39. Hillemann D, Kubica T, Agzamova R, Venera B, Rusch-Gerdes S, Niemann S: Rifampicin and isoniazid resistance mutations in Mycobacterium tuberculosis strains isolated from patients in Kazakhstan. Int J Tuberc Lung Dis 2005, 9(10):1161-1167.

\section{Pre-publication history}

The pre-publication history for this paper can be accessed here: http://www.biomedcentral.com/1471-2334/11/77/prepub

doi:10.1186/1471-2334-11-77

Cite this article as: Dymova et al:: Genetic variation of Mycobacterium tuberculosis circulating in Kharkiv Oblast, Ukraine. BMC Infectious Diseases 2011 11:77.

\section{Submit your next manuscript to BioMed Central and take full advantage of:}

- Convenient online submission

- Thorough peer review

- No space constraints or color figure charges

- Immediate publication on acceptance

- Inclusion in PubMed, CAS, Scopus and Google Scholar

- Research which is freely available for redistribution

Submit your manuscript at www.biomedcentral.com/submit 